\title{
Effect of Washing and Drying Conditions on Dimensional Change in Various Articles of Knitted Clothing *
}

\author{
Yurika Hashimoto $^{\mathrm{a}}$, Kyoung Ok Kim ${ }^{\mathrm{b}, \mathrm{c}}$, \\ Kazuhiko Hashimoto ${ }^{\mathrm{d}}$, Masayuki Takatera ${ }^{\mathrm{b}, \mathrm{c}, *}$ \\ ${ }^{a}$ Graduate School of Science and Technology, Shinshu University, 3-15-1 Tokida, Ueda-shi, \\ Nagano 386-8567, Japan \\ ${ }^{\mathrm{b}}$ Division of Kansei and Fashion Engineering, Institute for Fiber Engineering (IFES), Interdisciplinary \\ Cluster for Cutting Edge Research (ICCER), Shinshu University, 3-15-1 Tokida, Ueda-shi, \\ Nagano 386-8567, Japan \\ ${ }^{\mathrm{c}}$ Faculty of Textile Science and Technology, Shinshu University, 3-15-1 Tokida, Ueda-shi, \\ Nagano 386-8567, Japan \\ d Panasonic Corporation, 2-3-1-2 Noji-higashi, Kusatsu City, Shiga 525-8555, Japan
}

\begin{abstract}
We investigated the effect of washing and drying conditions on dimensional change in various articles of knitted clothing, taking into account drying temperature, temperature change during drying, external force at dehydration, external force during drying, and humidity during drying. We immersed samples in water at $25 \pm 2{ }^{\circ} \mathrm{C}$ for $30 \mathrm{~min}$, then dried them in a chamber at 40,60 , and $80{ }^{\circ} \mathrm{C}$, and at $5 \%$ relative humidity $(\mathrm{RH})$. We also investigated the effects of increasing the temperature from 40 to $60{ }^{\circ} \mathrm{C}$ and decreasing it from 60 to $40{ }^{\circ} \mathrm{C}$. After dehydration, we dried the samples using a roller and a frontloader washing and drying machine at various humidity levels. We measured dimensional changes in the samples before and after drying. We investigated five samples of knitted clothing: men's socks, women's socks, men's underwear, women's underwear, and women's t-shirts. We detected no difference in the dimensional change ratio in the cotton or polyurethane underwear and t-shirts when the drying temperature was varied. However, the dimensional change ratio of acrylic-containing men's socks varied depending on the drying temperature. When drying acrylic-containing men's socks from 40 to $60{ }^{\circ} \mathrm{C}$, the dimensional change ratio was larger than under other drying conditions. A lower temperature in the final drying stage could effectively reduce the shrinkage of socks made from acrylic, polyester, and polyurethane. The deformation due to external force during dehydration affected dimensional change. The external force during drying also greatly affected dimensional change in the knitted clothing. The humidity and drying time did not affect dimensional change in the knitted cotton clothing.
\end{abstract}

Keywords: Shrinkage; Knitted clothing; Drying temperature; Knitted fabric

\footnotetext{
${ }^{\star}$ Project supported by the Japan Society for the Promotion of Science (JSPS) KAKENHI (grant numbers $16 \mathrm{~K} 16255$ and 17H01955).

* Corresponding author.

Email address: takatera@shinshu-u.ac.jp (Masayuki Takatera).
} 


\section{Introduction}

Knitted fabric has been widely used for various types of clothing such as t-shirts, trousers, skirts, and socks. Knitwear is comfortable owing to its high extensibility. However, there are unsatisfactory aspects to knitwear such as dimensional changes, pilling, and changes to the "hand" of the fabric. Among these disadvantages, the shrinkage of the knitted fabric after washing and drying is one of the major causes of consumer dissatisfaction. Therefore, it is necessary to investigate the reason for shrinkage.

Many researchers have investigated the factors that affect the shrinkage of different types of knitted fabrics, and have considered the material, structure, finish, laundering conditions, etc. Fletcher et al. [1] investigated dimensional changes in knitwear made from various materials during laundering by measuring the spacings of the wale and course, and reported rearrangement of the fabric structure. Abbott et al. [2] investigated the mechanism of fabric shrinkage, taking into account the role of fiber swelling. Suh [3] also investigated the shrinkage of cotton jersey fabric by conducting a geometrical analysis of loop reorientation resulting from yarn swelling. He determined that the length shrinkage of a plain knitted cotton fabric depends mainly on two phenomena: loop migration and the change in course curvature. Other parameters in addition to fiber swelling have been investigated by many researchers. Onal and Candan [4] also investigated fabric shrinkage statistically and experimentally, taking into account knit characteristics and wet treatments. They found that fabric shrinkage is strongly affected by the type of yarn and the blend of the fiber. Quaynor et al. [5] investigated dimensional changes in knitted silk and cotton fabrics during laundering. They demonstrated that cotton shrinks more than silk. Mckinney and Broome [6] investigated the dimensional differences between knitted jersey fabrics made with open-end and ring-spun yarns; the fabric made from open-end yarns had relatively good dimensional stability.

Laundering conditions also affect the shrinkage of knitted fabric. Van Amber et al. [7] investigated the effects of laundering and water temperature on the properties of silk and silk-blend knitted fabrics. Anand et al. [8] investigated the effects of washing and drying conditions on the dimensional stability and distortion of knitted fabrics during laundering with a detergent. Quaynor et al. [9] investigated the effects of laundering and laundering temperatures on the surface properties and dimensional stability of plain flat knit silk, cotton, and polyester fabrics with varying cover factors. However, they did not specifically investigate the effect of drying temperature on dimensional stability.

Drying machines are now used in the home, and drying as well as washing conditions affect dimensional stability. Therefore, it is also necessary to investigate the effect of drying conditions on dimensional changes. Higgins et al. [10] investigated the effects of various home laundering practices on the dimensional stability, wrinkling, and other properties of cotton plain woven fabrics. They also investigated the effect of the rinse cycle softener and drying method, and the effects of tumble sheet softener and tumble drying time [11]. Mikučionienė and Laureckienè [12] investigated the behavior of knitted fabric during drying under various conditions, and the influence of these conditions on the dimensional stability of finished knitwear. However, the effect of drying temperature on the dimensional changes in various knitted clothing - excluding other factors such as gravity and wind - remains unclear. Hashimoto et al. [13] investigated the influence of drying temperature on the shrinkage of various knitted clothes. However, temperature changes during drying could affect the dimensional changes in knitted fabrics. Therefore, in the present study, we investigated the effect of washing and drying conditions on the shrinkage of 
various articles of knitted clothing. Moreover, we investigated the effect of external force during dehydration and drying. Finally, we investigated the effect of humidity during drying on the dimensional changes of the knitted fabrics.

\section{Experimental}

We investigated the dimensional changes in several articles of knitted clothing under various washing and drying conditions. Fabric samples, on which the same lines were drawn, were preconditioned for $60 \mathrm{~min}$ in a chamber at $40{ }^{\circ} \mathrm{C}$ and $5 \%$ relative humidity $(\mathrm{RH})$. After preconditioning, the samples were considered to be in an "Initial dry state". The sample masses and lines were measured for reference. The samples were then immersed in water for $30 \mathrm{~min}$ at $25 \pm 2{ }^{\circ} \mathrm{C}$. After immersion, the samples were considered to be in an "After immersing and squeezing state". The samples were then dried under the following conditions. During drying, we measured the mass every 30 min. When the moisture content fell below 1\%, or when there was no change in mass, we considered the fabric to be in an "After drying state", and the dimensional change ratio was calculated based on Japanese Industrial Standard (JIS) L 1096 8.39 [14]. We then calculated the average of the dimensional change ratios in the wale and course directions. The dimensional change ratio was calculated using Equation (1). Multiple comparison tests were carried out using the Tukey method.

$$
\Delta L=\frac{L_{2}-L_{1}}{L_{1}} \times 100
$$

$\Delta L$ : dimensional change ratio $(\%) ; L_{1}$ : initial length $(\mathrm{mm}) ; L_{2}$ : length after drying $(\mathrm{mm})$.

\subsection{Drying temperatures}

When the samples were in the "After immersing and squeezing state", we dried them in a chamber at 40,60 , and $80^{\circ} \mathrm{C}$, and $5 \% \mathrm{RH}[13]$.

\subsection{Temperature variation during drying}

When the samples were in the "After immersing and squeezing state", we varied the temperature during drying. We did not dehydrate the samples in this part of the experiment. We applied the following drying procedures: $40{ }^{\circ} \mathrm{C}$ throughout; $40{ }^{\circ} \mathrm{C}$ increasing to $60{ }^{\circ} \mathrm{C} ; 60{ }^{\circ} \mathrm{C}$ decreasing to $40{ }^{\circ} \mathrm{C}$; and $60{ }^{\circ} \mathrm{C}$ throughout. We measured the moisture contents and dimensional change ratios of the samples after each temperature regimen. We also measured the temperature and humidity inside the chamber and the clothing during drying, using a temperature and humidity logger.

\subsection{Overdrying after the drying state}

When the samples were in the "After immersing and squeezing state", we dried them at 40 and $80{ }^{\circ} \mathrm{C}$. We did not dehydrate the samples. When the samples were in the "After drying state", we overdried them for a further $6 \mathrm{~h}$. 


\subsection{External force during dehydration}

When samples were in the "After immersing and squeezing state", we applied three different approaches to dehydration. The first was dehydrating using rollers; we inserted each sample between two rollers and dehydrated it by turning the rollers in one direction. The second approach involved dehydrating each sample using the dehydration function of a front-loader washing and drying machine (NA-V81, Panasonic Corporation, Japan). The third approach was no dehydration. After dehydration, we dried each sample in a chamber at $40{ }^{\circ} \mathrm{C}$ and $5 \% \mathrm{RH}$.

\subsection{External force during drying}

When the samples were in the "After immersing and squeezing state", we dehydrated them using a roller and a front-loader washing and drying machine. To maintain a constant moisture content, we dehydrated each sample using a roller until the moisture content reached $70-80 \%$. Thus, the roller turning time varied depending on the sample. After dehydration, we dried the samples using a front-loader washing and drying machine (the tumble dry method; NA-V81, Panasonic Corporation, Japan), and by placing the samples flat over a net (the flat dry method) in a chamber at $40{ }^{\circ} \mathrm{C}$ and $5 \% \mathrm{RH}$.

\subsection{Environmental humidity during drying}

When the samples were in the "After immersing and squeezing state", we dehydrated them using a roller to maintain a constant moisture content. We dehydrated each sample until the moisture content reached 70 to $80 \% \mathrm{RH}$. When dehydration was complete, we dried the samples using the flat dry method in a chamber at $40{ }^{\circ} \mathrm{C}$ and $5 \% \mathrm{RH}, 40{ }^{\circ} \mathrm{C}$ and $40 \% \mathrm{RH}$, and $40{ }^{\circ} \mathrm{C}$ and $70 \% \mathrm{RH}$.

\subsection{Experimental samples}

One cotton fabric and five articles of knitted clothing were used as samples: men's socks, women's socks, men's underwear, women's underwear, and women's t-shirts. The sample details are shown

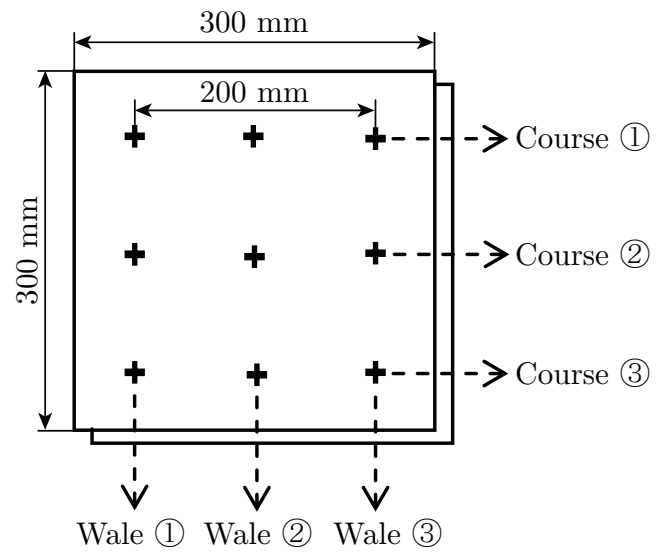

(a) Cut fabric samples

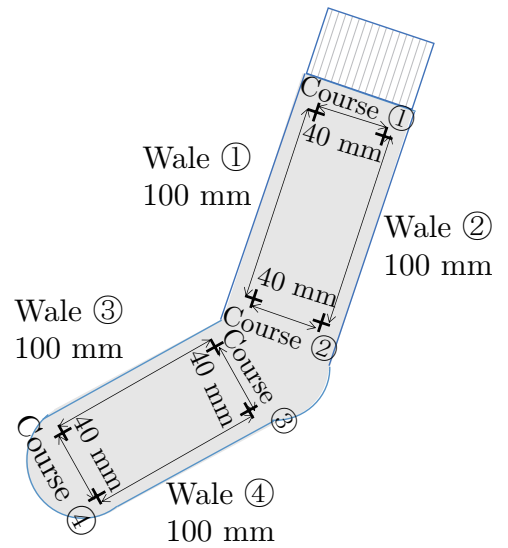

(b) Socks

Fig. 1: Measurement of sample points 
in Table 1. Except for the socks samples, the cotton fabric, underwear, and t-shirts were cut into $300 \mathrm{~mm} \times 300 \mathrm{~mm}$ squares. On those samples we marked three measurement points in the wale direction and three measurement points in the course direction at intervals of $100 \mathrm{~mm}$, as shown in Fig. 1(a). We used a $200 \mathrm{~mm} \times 200 \mathrm{~mm}$ square for the dimensional change ratio. For the socks, we took four measuring points at intervals of $100 \mathrm{~mm}$ in the wale direction and four measuring points at intervals of $40 \mathrm{~mm}$ in the course direction, as shown in Fig. 1(b), and calculated the dimensional change ratio for each part. There were five samples of each type of textile, except for the socks. There were four sock samples. We used all the samples for experiment 2.1, men's socks for experiment 2.2, cotton fabric and men's socks for experiment 2.3, and cotton fabric for experiments 2.4-6.

Table 1: Sample details

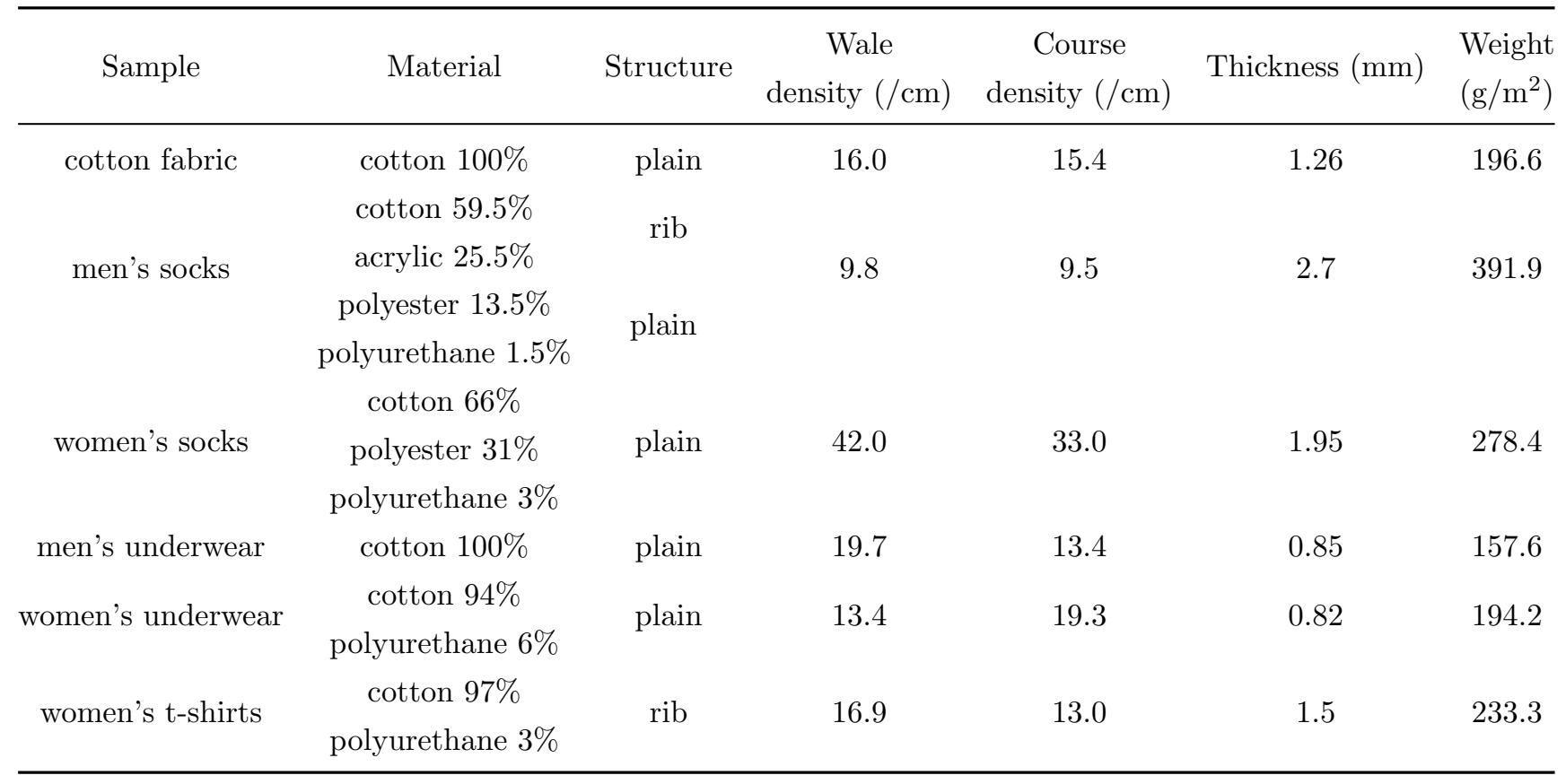

\section{Results and Discussion}

\subsection{Constant drying temperatures}

Fig. 2 shows the dimensional change ratio of the cotton fabric at each drying temperature. The dimensional change ratio from the "Initial state" (I) to the "After immersing and squeezing state" (A) (represented as I-A in the Figures) was larger than that from the "After immersing and squeezing state" to the "After drying state" (D) (represented as A-D in the Figures) in both the wale and course directions. However, there was only a significant difference in the dimensional change ratio $(5 \%)$ between 60 and $80{ }^{\circ} \mathrm{C}$ in the wale direction for I-D and I-A.

Regarding men's socks, the dimensional change ratio increased as the drying temperature increased, as shown in Figs. 3 and 4 . In both the wale and course directions, it shrank markedly during high-temperature drying. This could have been due to the acrylic fiber [15].

Figs. 5 and 6 show the dimensional change ratios in women's socks during changes to the 


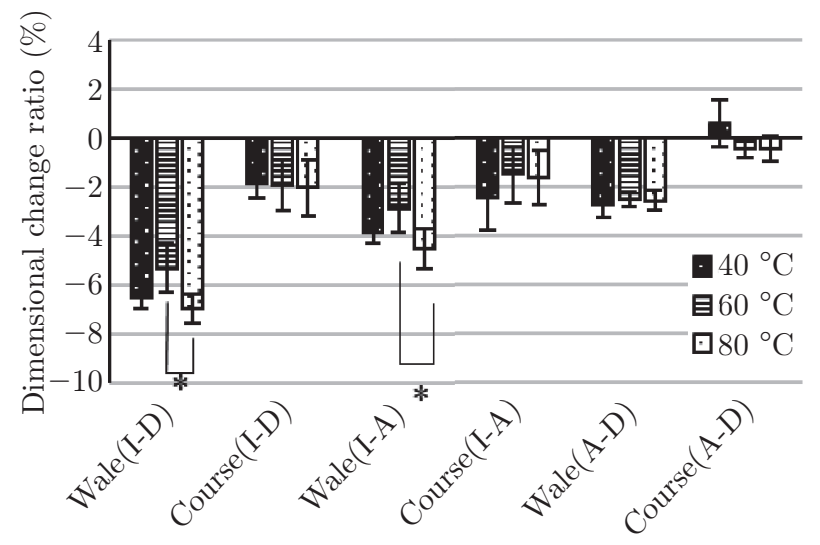

Fig. 2: Dimensional change ratios in cotton fabrics at various drying temperatures $(*$ Significance level $5 \%$ )

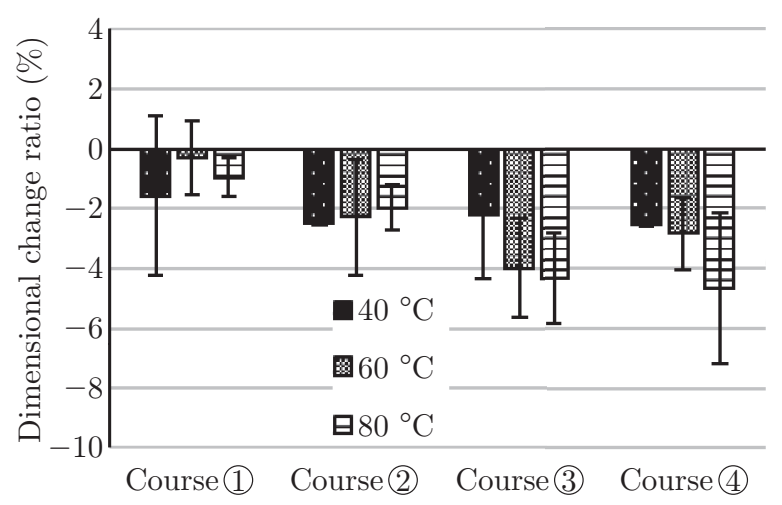

Fig. 4: Dimensional change ratios in men's socks at various drying temperatures in the course direction

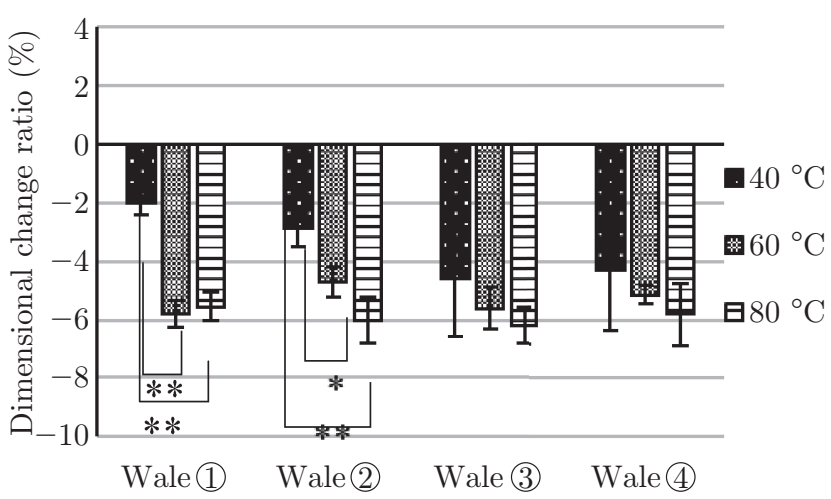

Fig. 3: Dimensional change ratios in men's socks at various drying temperatures in the wale direction (*Significance level 5\%; **Significance level 1\%)

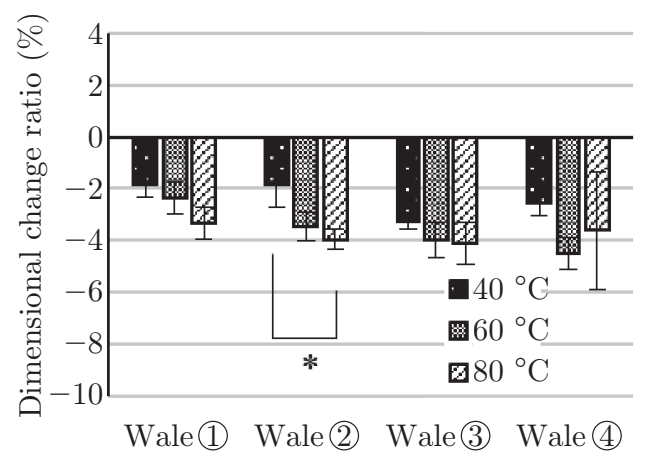

Fig. 5: Dimensional change ratios in women's socks at various drying temperatures in the wale direction (*Significance level 5\%)

drying temperature. Regarding women's socks, the dimensional change ratio increased during high-temperature drying. However, noticeable shrinkage was not as apparent as in the men's socks. Furthermore, the variation in course direction was larger than in the wale direction owing to the short measurement length in the course direction.

Fig. 7 shows the dimensional change ratio in men's underwear during changes to the drying temperature. Regarding the men's underwear, there was no difference in shrinkage due to the drying temperature. As with the cotton fabric, the dimensional change ratio of the men's underwear was not dependent on the drying temperature. The cotton fabric and the men's underwear were both made of $100 \%$ cotton. Therefore, it is clear that the shrinkage of cotton fabric is not affected by drying temperature.

Fig. 8 shows the dimensional change ratio in women's underwear during changes to the drying temperature. Regarding women's underwear containing polyurethane, there was no difference in shrinkage due to the drying temperature. Therefore, polyurethane is not affected by the drying temperature.

Regarding the women's t-shirts with rib structures, there was no difference in the dimensional change ratio with drying temperature, as shown in Fig. 9. Therefore, it is clear that knitted structures are not affected by the drying temperature. 


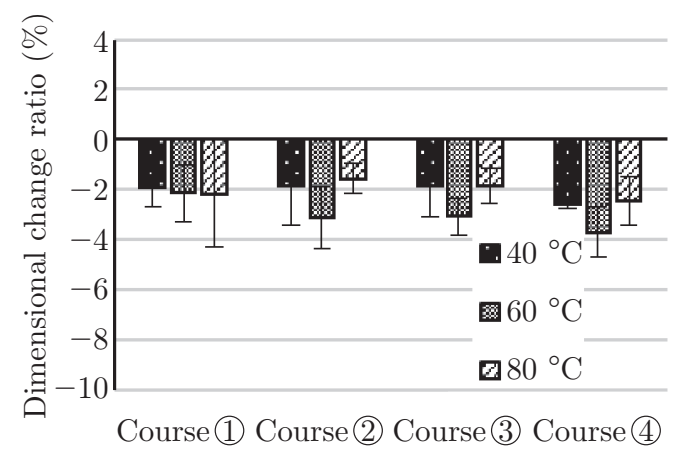

Fig. 6: Dimensional change ratios in women's socks at various drying temperatures in the course direction

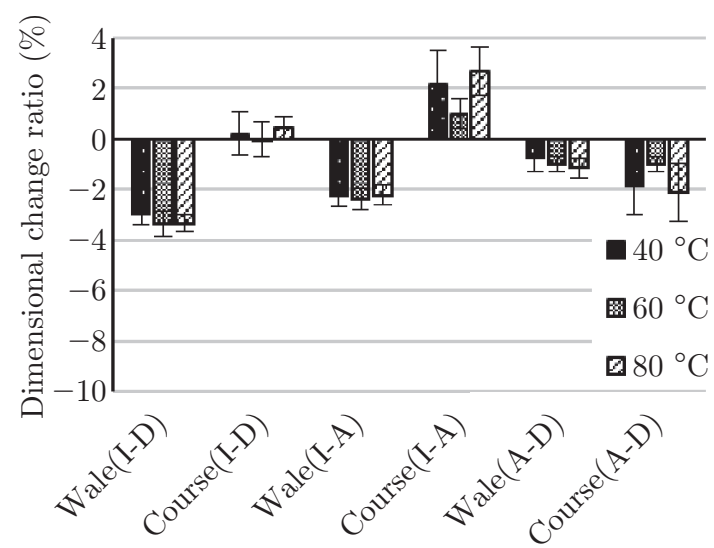

Fig. 8: Dimensional change ratios in women's underwear at various drying temperatures

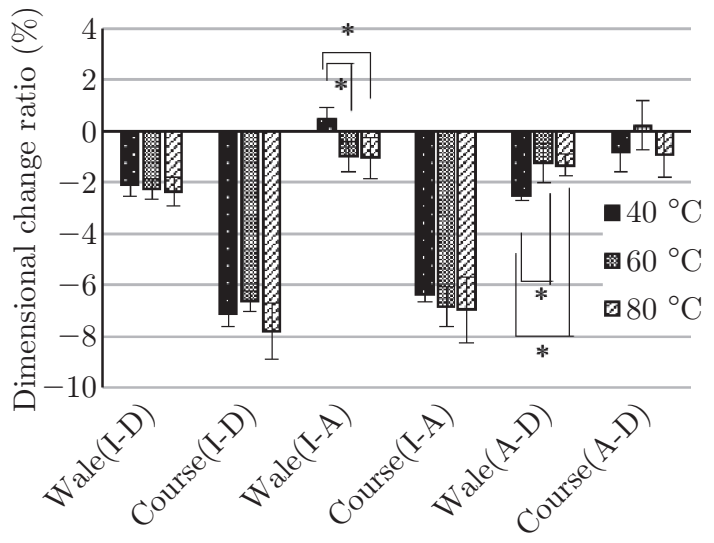

Fig. 7: Dimensional change ratios in men's underwear at various drying temperatures (*Significance level $5 \%$ )

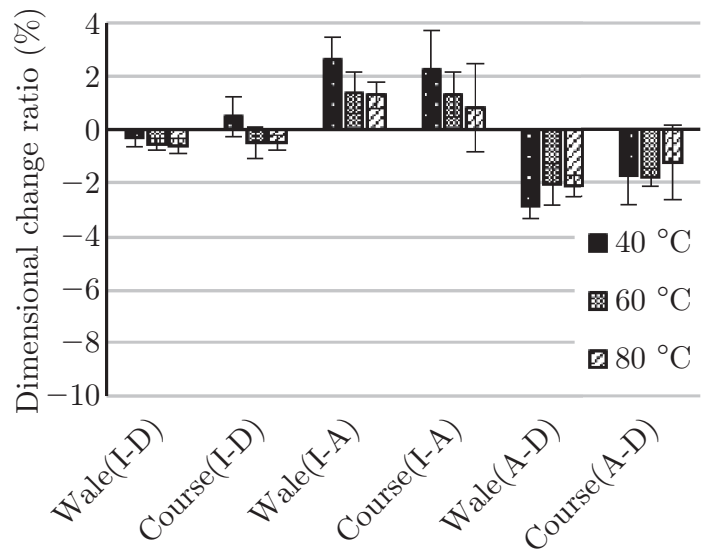

Fig. 9: Dimensional change ratios in women's tshirts at various drying temperatures

\subsection{Temperature change during drying}

Figs. 10 and 11 show the temperature and humidity changes of the socks inside the chamber. Fig. 10 shows the temperature and humidity changes when the temperature was increased from 40 to $60{ }^{\circ} \mathrm{C}$, and Fig. 11 shows the temperature and humidity changes when the temperature was decreased from 60 to $40{ }^{\circ} \mathrm{C}$. The temperature inside the clothes rose sharply when the socks dried out.

Figs. 12 and 13 show the dimensional change ratio according to drying temperature conditions in the wale and course directions. The dimensional change ratio at $40{ }^{\circ} \mathrm{C}$ was smallest in the wale direction. The dimensional change ratio when the drying temperature increased from 40 to $60{ }^{\circ} \mathrm{C}$ was greater than the dimensional change ratio when the drying temperature was maintained at $60{ }^{\circ} \mathrm{C}$. There were many significant differences in wales and, mostly between the $40{ }^{\circ} \mathrm{C}$ and the 40 to $60{ }^{\circ} \mathrm{C}$ scenarios. As the moisture content decreased, the temperature of the socks increased to the chamber temperature. This may have been caused by the high temperature at the end of the drying process. A lower temperature during the final drying process could effectively reduce the shrinkage of socks made of acrylic, polyester, and polyurethane by lowering the temperature 


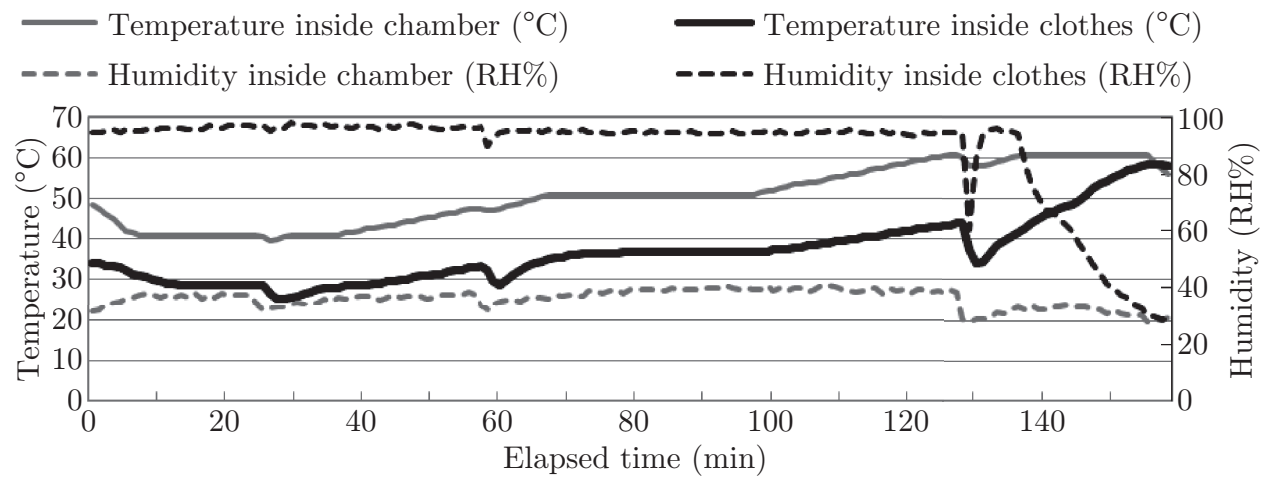

Fig. 10: Temperature and humidity changes in the chamber and in the socks $\left(40{ }^{\circ} \mathrm{C} \rightarrow 60{ }^{\circ} \mathrm{C}\right)$

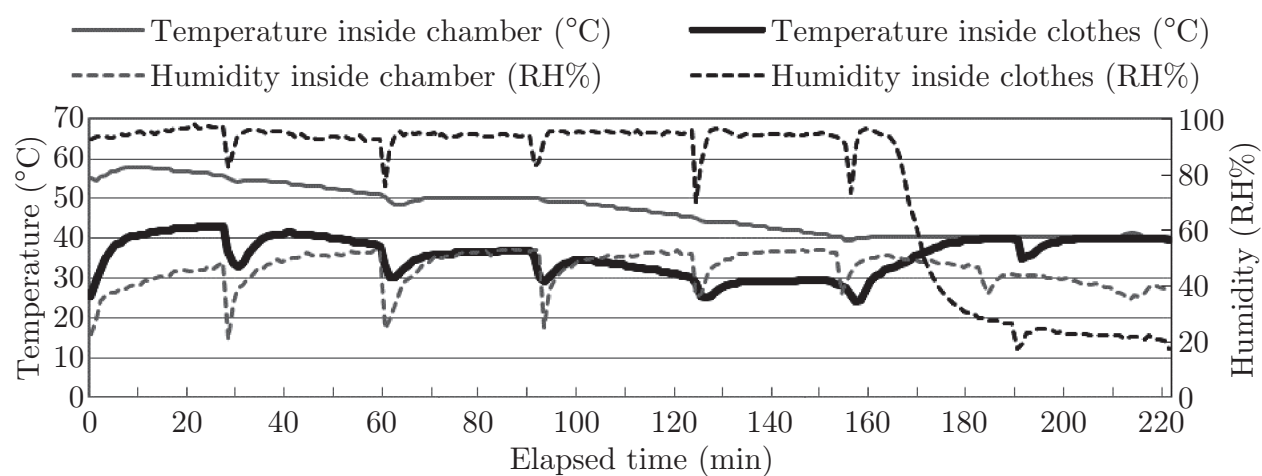

Fig. 11: Temperature and humidity changes in the chamber and in the socks $\left(60{ }^{\circ} \mathrm{C} \rightarrow 40{ }^{\circ} \mathrm{C}\right)$

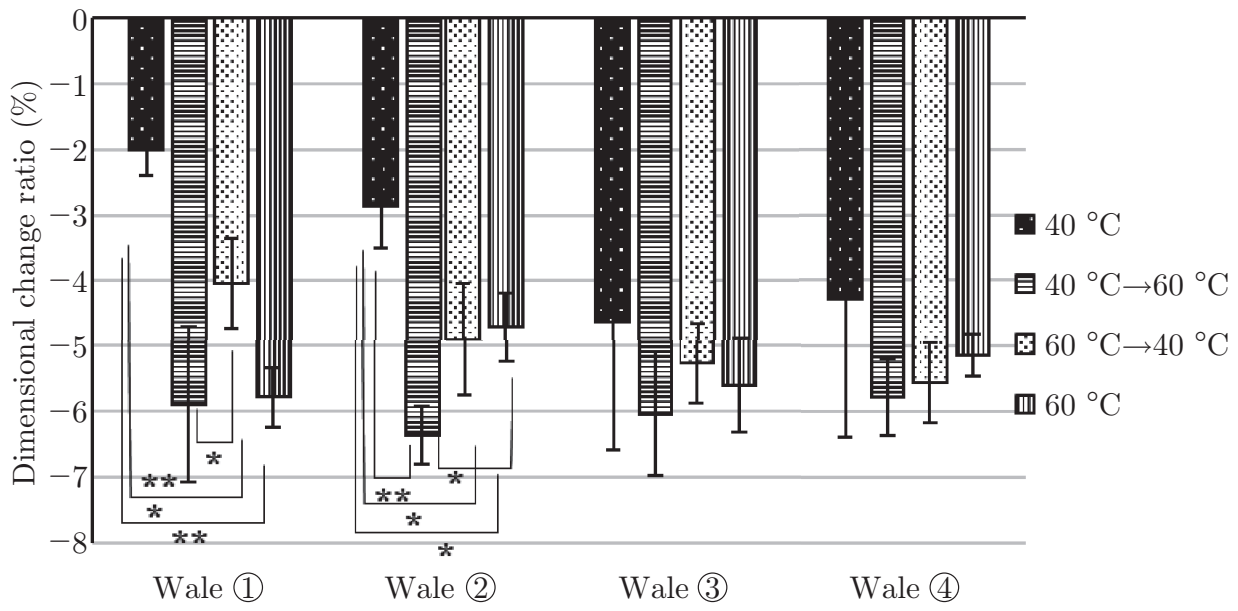

Fig. 12: Dimensional change ratios under various drying conditions (socks in the wale direction) (*Significance level 5\%; **Significance level 1\%)

inside the clothes.

\subsection{Overdrying after drying state}

Fig. 14 shows the dimensional change ratios of the cotton fabric following overdrying. Figs. 15 and 16 show the dimensional change ratios in men's socks in the wale and course directions 


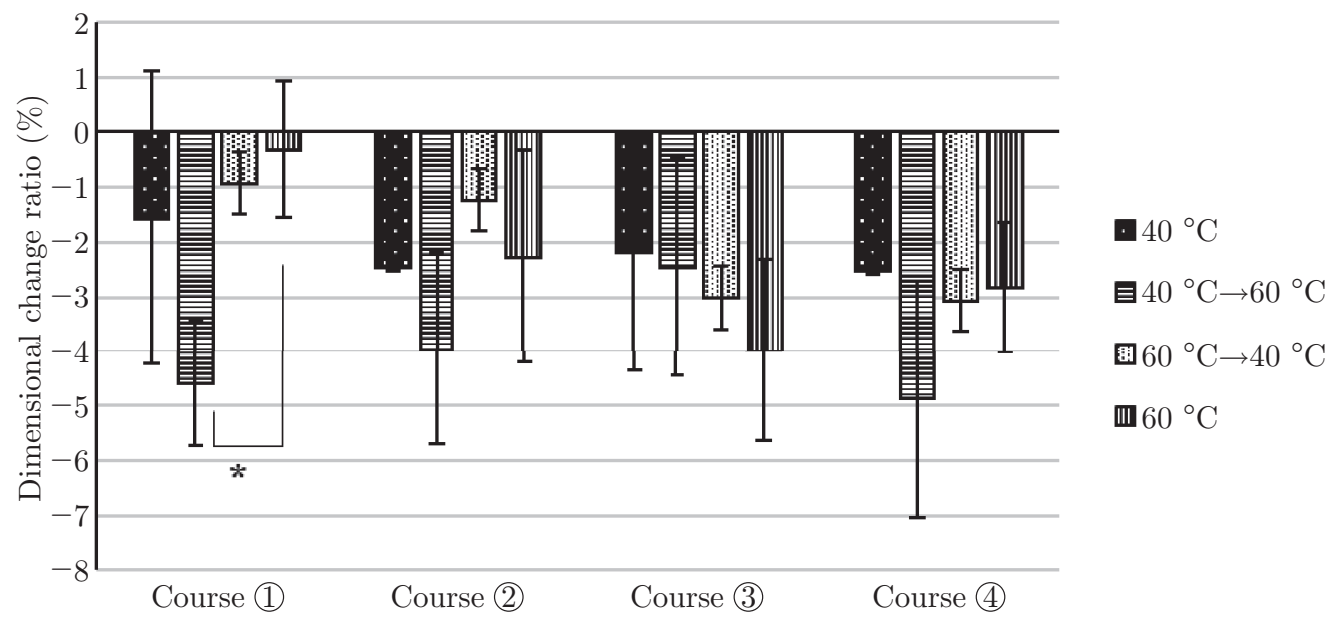

Fig. 13: Dimensional change ratios under various drying conditions (socks in the course direction) (*Significance level 5\%)

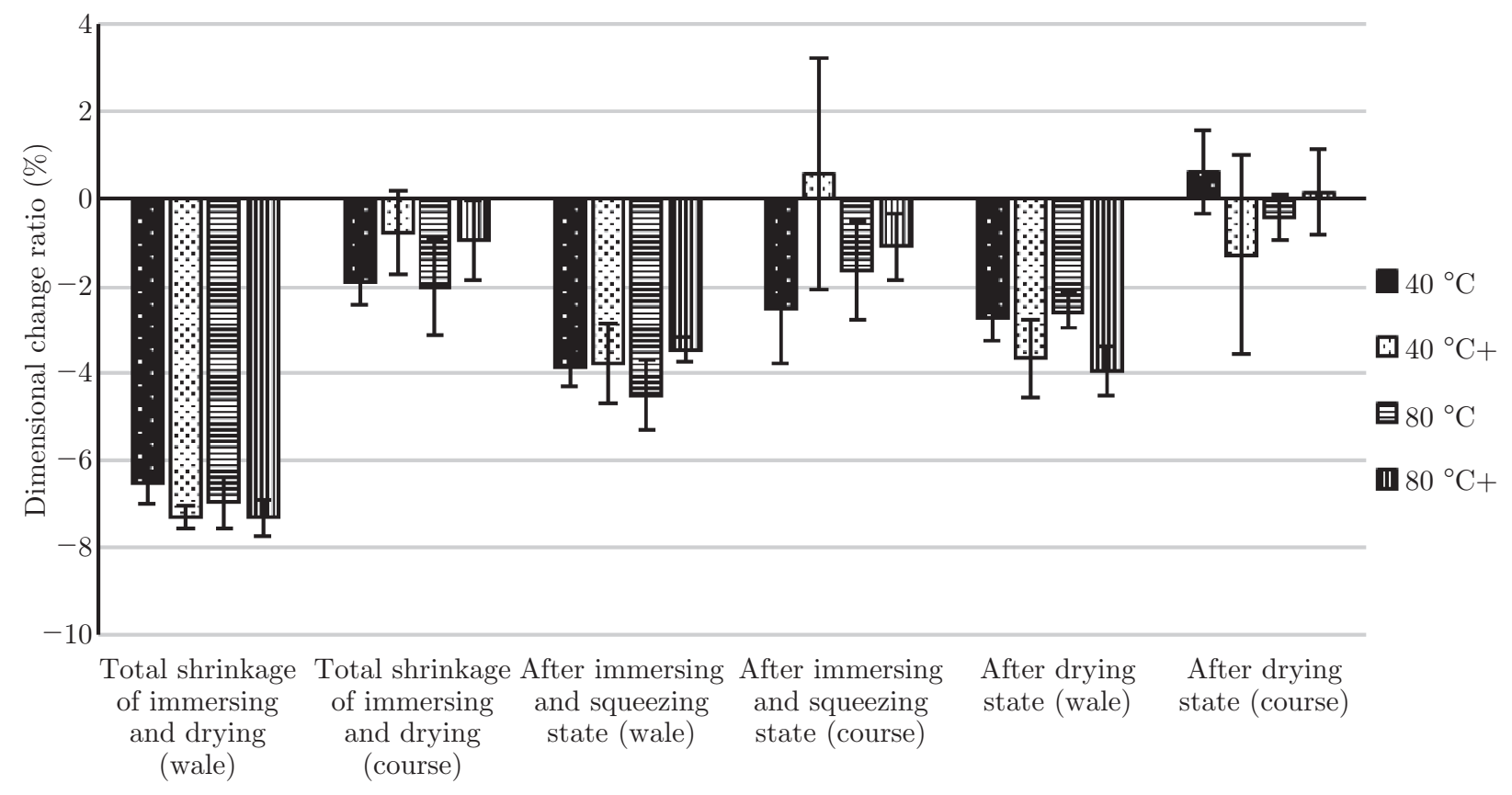

Fig. 14: Dimensional change ratios of the cotton fabric during overdrying

following overdrying. Regarding the cotton knitted fabric, there was no significant difference in the dimensional change ratio, even following overdrying. The socks shrank markedly in both the wale and course directions following overdrying. It is clear that overdrying can cause the socks to shrink. This result is related to the results for the socks in section 3.2.

\subsection{External force during dehydration}

Fig. 17 shows the dimensional change ratios under various dehydration conditions. As shown in Fig. 17, there were significant differences between roller and no dehydration, and roller and dehydration at each state. In course direction, samples was elongated by dehydration using a roller. It is due to the force of the rollers occurring by turning it. Therefore, it has become 


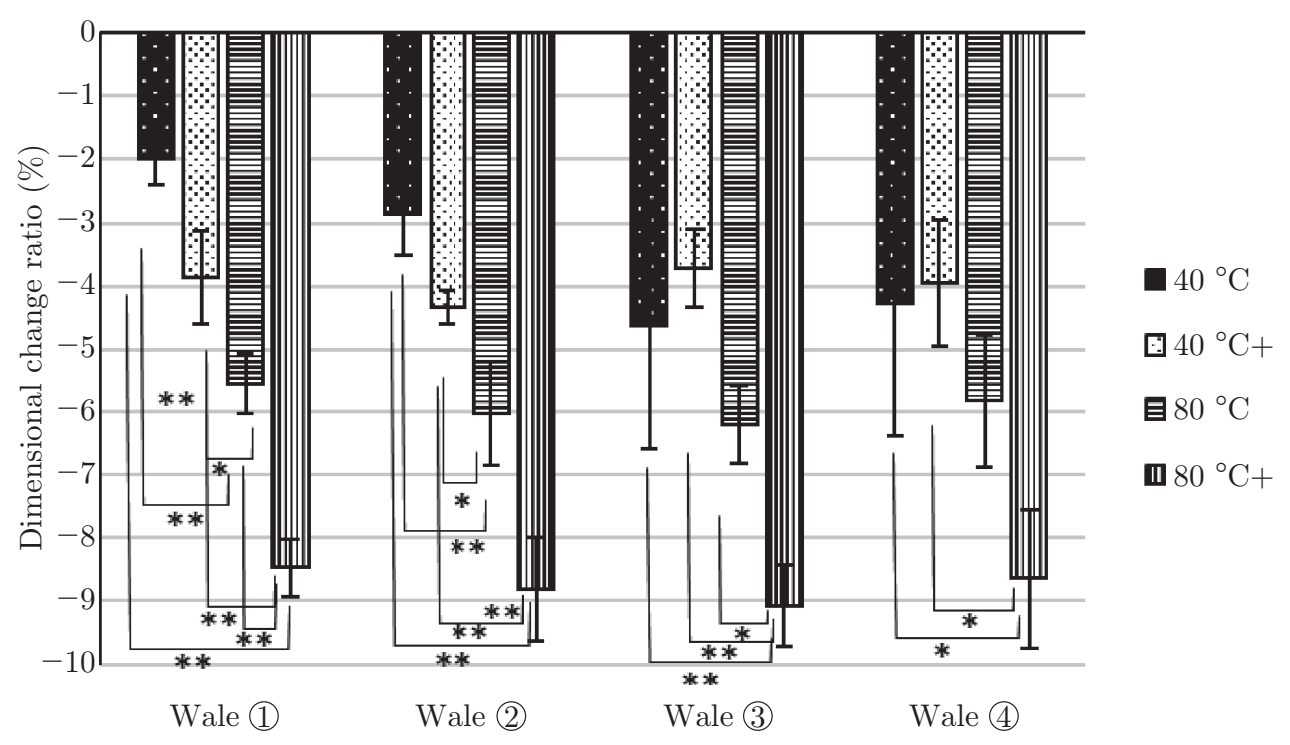

Fig. 15: Dimensional change ratios in men's socks during overdrying in the wale direction (*Significance level 5\%; **Significance level 1\%)

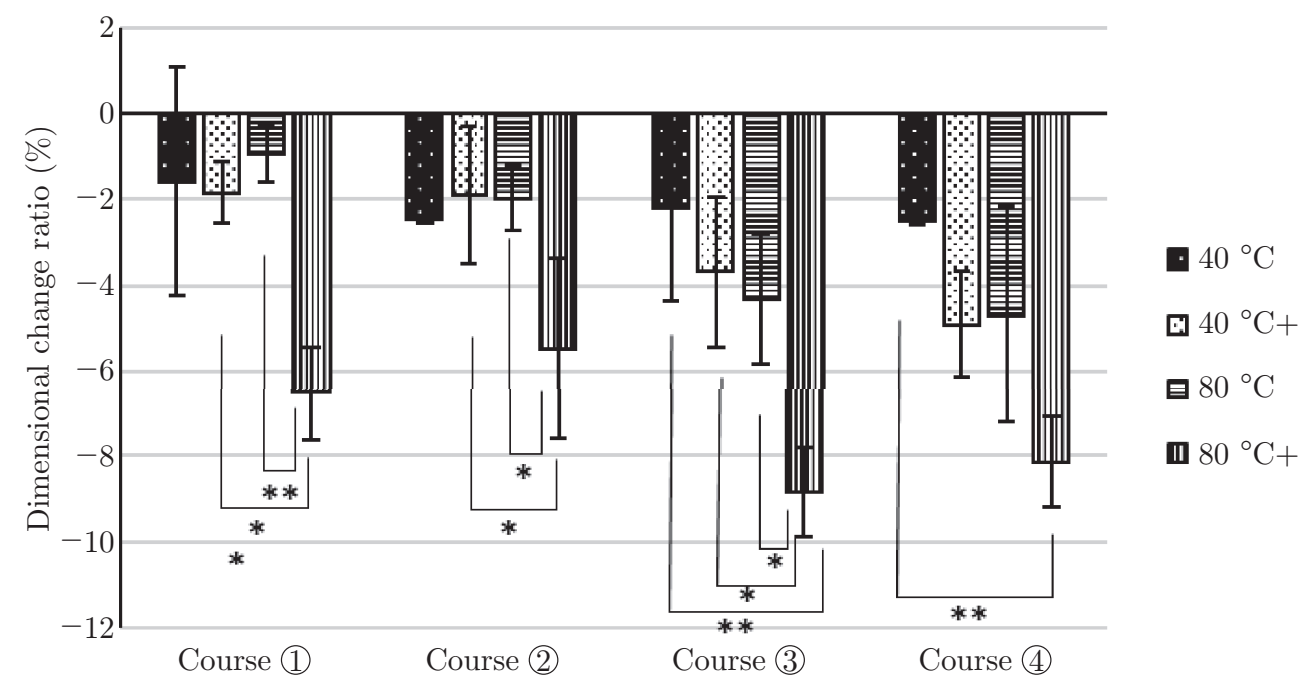

Fig. 16: Dimensional change ratios in men's socks during overdrying in the course direction (*Significance level 5\%; **Significance level 1\%)

clear that the deformation due to the external force affected the dimensional changes by drying of cotton.

\subsection{External force during drying}

Fig. 18 shows the dimensional change ratios under the various drying conditions. There were significant differences of $1 \%$ in both the wale and course directions between the dimensional change ratios of the flat-dried and tumble-dried samples, except in wale (I-A). There was a significant difference of $5 \%$ between the dimensional change ratios of the flat-dried and tumble-dried samples in course (I-A), even though the same dehydration method (rolling) was used. Thus, the reason for the difference in dimensional change ratios could be due to the turning time of the rollers 


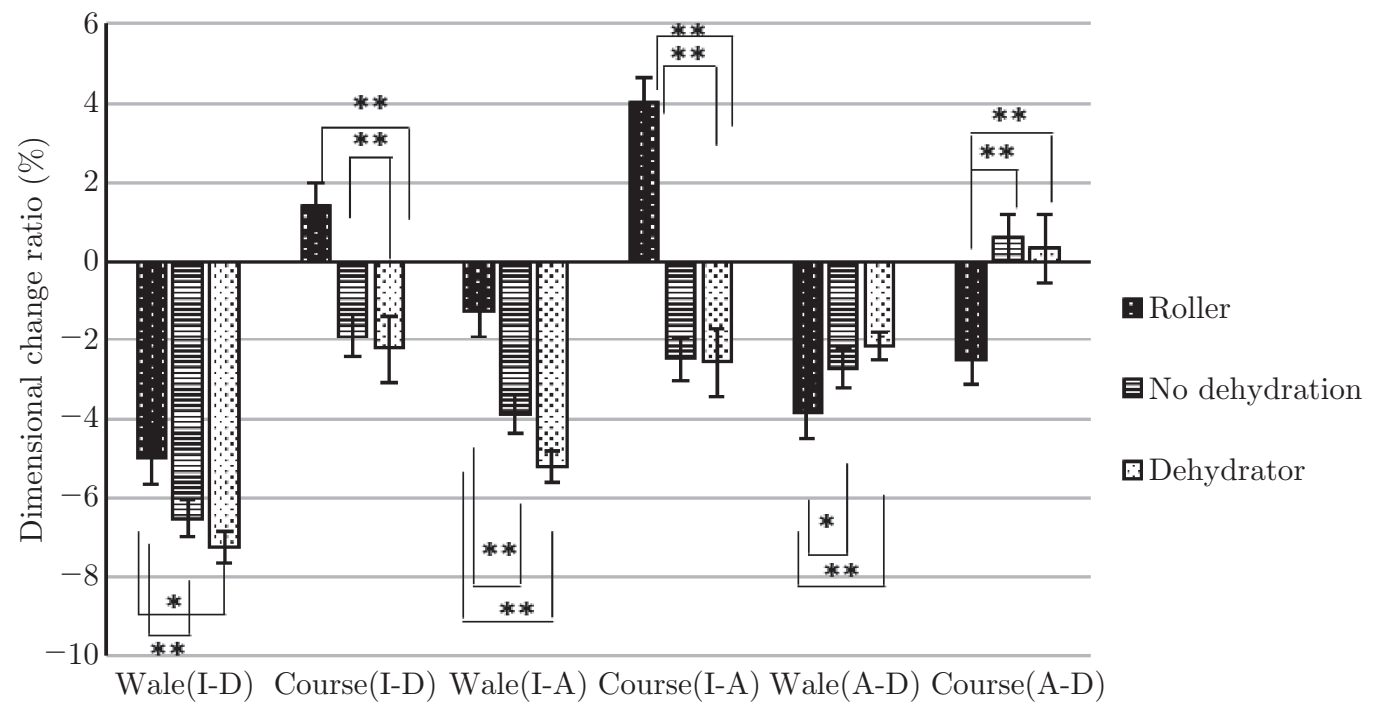

Fig. 17: Dimensional change ratios under various dehydration conditions (*Significance level 5\%; **Significance level 1\%)

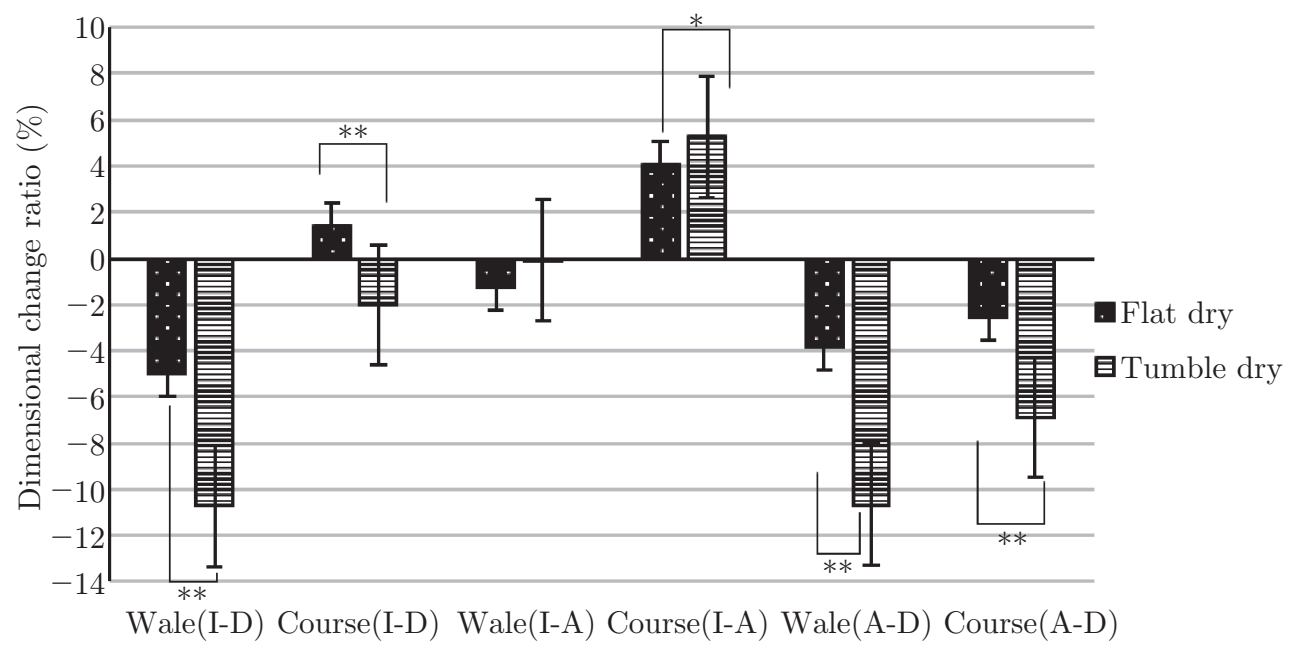

Fig. 18: Dimensional change ratios under the various drying methods (*Significance level 5\%; **Significance level 1\%)

necessary to achieve the same moisture content of $70-80 \%$. When the tumble dry method was used, a significant difference of $1 \%$ was observed between the dimensional change ratios of flatdried and tumble-dried samples in wale (A-D) and course (A-D), and the samples were markedly shrunken. Therefore, the external force during drying has a marked effect on the dimensional change ratio of knitted cotton fabrics.

\subsection{Environmental humidity during drying}

Fig. 19 shows the moisture contents of the samples versus drying time. The drying time varied according to environmental humidity. At $5 \% \mathrm{RH}$, the drying time was $1.5 \mathrm{~h}$. At $40 \% \mathrm{RH}$ and $70 \% \mathrm{RH}$, the drying times were 2 and $3.5 \mathrm{~h}$, respectively. At $40 \% \mathrm{RH}$ and $70 \% \mathrm{RH}$, the moisture contents of the samples $(2.8 \%$ and $6.1 \%$, respectively) did not change. Thus, samples with such 
moisture contents were considered to be in the "After drying state". Fig. 20 shows the dimensional change ratios of the knitted clothing samples at various drying humidity levels. Although the drying time changed according to the environmental humidity, there were no significant differences in the dimensional change ratios. Thus, the environmental humidity and drying time do not affect the dimensional change ratios of knitted cotton fabrics.

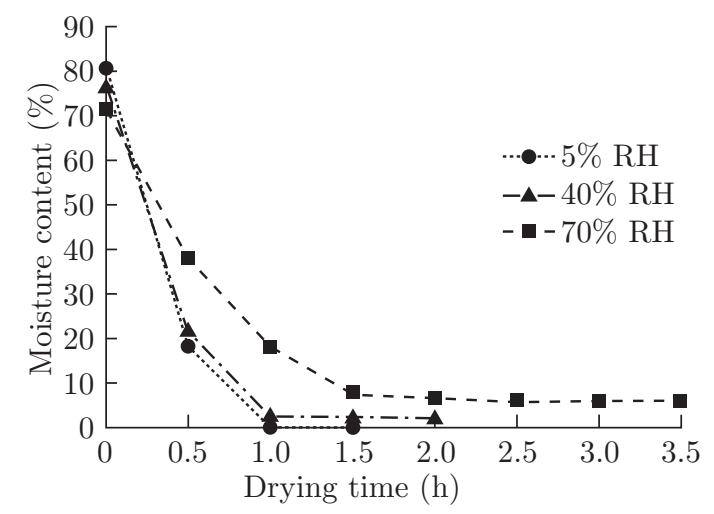

Fig. 19: Relationship between drying time and moisture content of the samples at various humidity levels

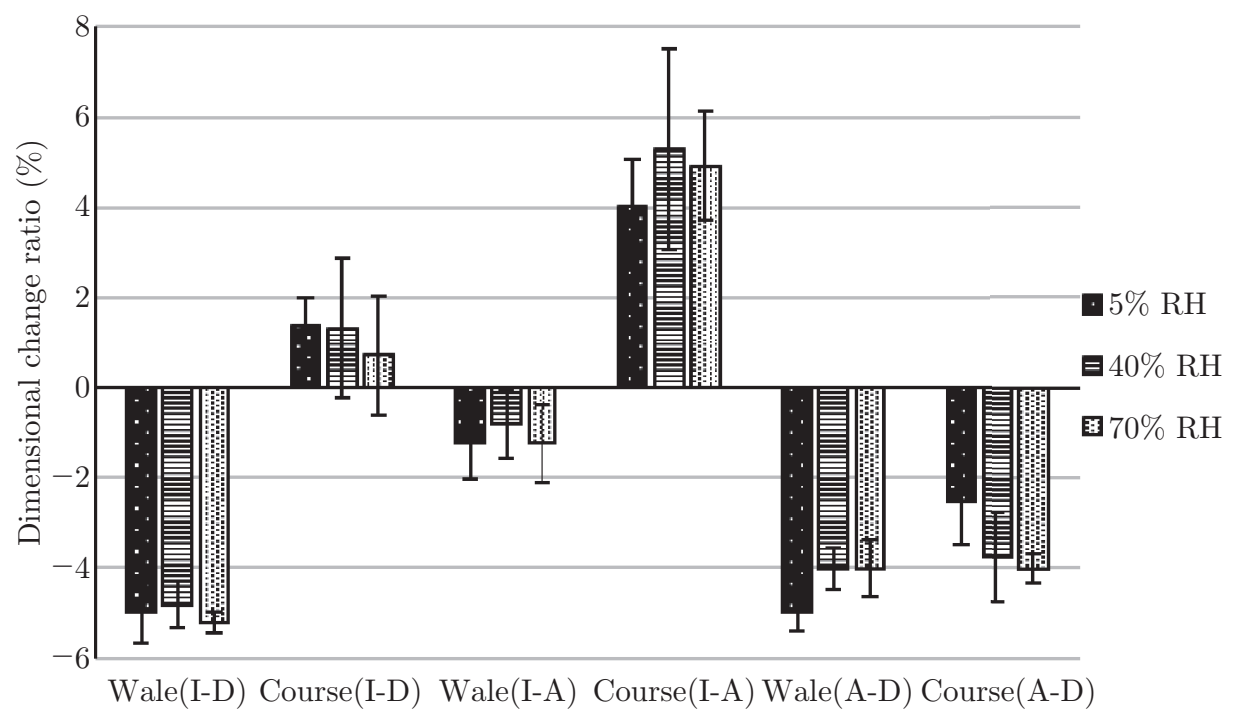

Fig. 20: Dimensional change ratios at various drying humidity levels

\section{Conclusion}

By varying the drying temperature, we determined that there were no differences in the dimensional change ratios of the underwear and T-shirts, which were made from cotton and polyurethane. However, depending on the drying temperature, there was a difference in the dimensional change ratios between the two kinds of socks containing acrylic, polyester, and polyurethane. The large dimensional change ratio at high temperature of the socks containing acrylic could have been due to the acrylic. We found that fabrics made from polyurethane, 
fabrics with knitted structures, and fabrics with rib structures were not affected by drying at higher temperature.

When drying men's socks containing acrylic at temperatures increasing from 40 to $60{ }^{\circ} \mathrm{C}$, the dimensional change was larger than was the case under other drying conditions. The same results were observed during sample overdrying. Therefore, a lower temperature in the final drying process effectively reduces the shrinkage of socks made from acrylic.

The dimensional changes in response to the dehydration and drying conditions revealed that deformation in the wet state affected the final dimensional changes. Deformation due to external force affected the dimensional changes of the cotton fabrics during drying. External force during drying greatly affects the dimensional change ratios of cotton fabrics, but environmental humidity and drying time do not.

\section{Acknowledgments}

This work was supported by the Japan Society for the Promotion of Science (JSPS) KAKENHI (grant numbers 16K16255 and 17H01955).

\section{References}

[1] Fletcher H M, Roberts SH. Distortion in knit fabrics and its relation to shrinkage in laundering. Tex Res J 1953; 23(1): 37-42.

[2] Abbott NJ, Khoury F, Barish L. 10 - The mechanism of fabric shrinkage: the rôle of fibre swelling. J Text Inst 1964; 55(1): T111-T127.

[3] Suh MW. A study of the shrinkage of plain knitted cotton fabric, based on the structural changes of the loop geometry due to yarn swelling and deswelling. Tex Res J 1967; 37(5): 417-431.

[4] Onal L, Candan C. Contribution of fabric characteristics and laundering to shrinkage of weft knitted fabrics. Tex Res J 2003; 73(3): 187-191.

[5] Quaynor L, Takahashi M, Nakajima M. Dimensional changes in knitted silk and cotton fabrics with laundering. Tex Res J 1999; 69(4): 285-291.

[6] Mckinney M, Broome ER. The effects of laundering on the performance of open-end and ring-spun yarns in jersey knit fabrics. Tex Res J 1977; 47(3): 155-162.

[7] Van Amber RR, Niven BE, Wilson CA. Effects of laundering and water temperature on the properties of silk and silk-blend knitted fabrics. Tex Res J 2010; 80(15): 1557-1568.

[8] Anand SC, Brown KSM, Higgins LG, Holmes DA, Hall ME, Conrad D. Effect of laundering on the dimensional stability and distortion of knitted fabrics. Autex Res J 2002; 2(2): 85-100.

[9] Quaynor L, Takahashi M, Nakajima M. Effects of laundering on the surface properties and dimensional stability of plain knitted fabrics. Tex Res J 2000; 70(1): 28-35.

[10] Higgins L, Anand SC, Holmes DA, Hall ME, Underly K. Effects of various home laundering practices on the dimensional stability wrinkling, and other properties of plain woven cotton fabrics: Part I: Experimental overview, reproducibility of results, and effect of detergent. Tex Res J 2003; 73(4): 357-366.

[11] Higgins L, Anand SC, Holmes DA, Hall ME, Underly K. Effects of various home laundering practices on the dimensional stability, wrinkling, and other properties of plain woven cotton fabrics: 
Part II: Effect of rinse cycle softener and drying method and of tumble sheet softener and tumble drying time. Tex Res J 2003; 73(5): 407-420.

[12] Mikučionienè D, Laureckienè G. The influence of drying conditions on dimensional stability of cotton weft knitted fabrics. Mater Sci 2009; 15(1): 64-68.

[13] Hashimoto Y, Kim KO, Hashimoto K, Takatera M. Effect of dry condition on shrinkage of various knitted clothing, Proceedings of 11th Textile Bioengineering and Informatics Symposium (TBIS2018) 2018, 07: 25-28, Manchester, UK: 963-968.

[14] Japanese Standards Association, Japanese Industrial Standard (JIS) Handbook Sen’i, Japanese Standards Association, Tokyo, 2015.

[15] Hurley RB. The dimensional stability of acrylic knit fabrics. Tex Res J 1966; 36(11): 989-993. 